\title{
Altered Renal Expression of Nitric Oxide Synthase Is ozymes in Spontaneously Hypertensive Rats
}

Soo-Wan Kim, M.D., Kyung-Hyub Moon, M.D., Seong-Cheol Lee, M.D. Nam-Ho Kim, M.D., Dae-Gil Kang, Ph.D.*, Jong-Un Lee, M.D.* Ki-Chul Choi, M.D. and Young-Joon Kang, M.D.

Department of Inte rnal Medicine, Chonnam University Medical School and Hormone Research Center*, Chonnam National University, Kwangju, Korea

Objectives : The present study was aimed at exploring whether the pathogenesis of hypertension is related $w$ ith an altered expression of nitric ox ide synthase (NOS) isozymes, i.e., bNOS, iNOS and ecNOS.

Method : By Western blot analysis, the expression of NOS isozymes were determined in the kidney isolated from spontaneously hypertensive rats (SHR) and their normotensive control, Wistar-Kyoto rats (WKY). The NOx (nitrite/nitrate) contents we re also determined in the kidney and plasma.

Results : The plasma NOx was significantly increased in SHR compared with that in WKY. The basal level of NOx was higher in the medulla and cortex of the kidney in SHR compared with that in WKY rat. bNOS proteins were expressed higher in the outer medulla and cortex, and iNOS proteins were higher in the inner medulla, outer medulla and cortex in SHR. ecNOS expression did not significantly differ between the $S H R$ and $W K Y$.

Conclusions : These results indicate that the NO generation may not be impaired, but rather increased. It is likely that the increased expression of NOS isozymes is a counter-reactive phenomenon secondary to the increased blood pressure in this model of hypertension.

Key Wo rds : Pathogenesis of hypertension, Spontaneously hypertensive rats $(S H R)$, Nit ric oxide $(N O)$

\section{INT RODUCT ION}

Nitric oxide (NO), produced by the conversion of the terminal guanidino nitrogen atoms from L-arginine, accounts for many of the biological properties of endothe lium-derived relaxing factor $(E D R F)^{1)}$. NO synthesis is catalyzed by three distinct forms of nitric oxide synthases (NOS), i.e., brain (bNOS), inducible (iNOS) and endothelial constitutive (ecNOS) isozymes ${ }^{2)}$. The importance of NO in the physiological control of blood pressure is now well established. I causes

Address reprint requests to : Ki-Chul Choi, M.D., Ph.D., Department of Intemal Medicine, Chonnam University Medical School, 8 Hakdong, Kwangiu 501-757, Korea vascular relaxation by activation of soluble guanylate cyclase and, hence, increasing cyclic guanosine 3', 5 '- monophosphate (cGMP) levels in the smooth muscle ${ }^{3)}$. Therefore, an alteration in NO synthesis may be a $\mathrm{s}$ ignificant factor in the pathogenesis of hypertension. A decreased responsiveness to endothelium-dependent vasodilators is characteristically seen in isolated arteries from various models of experimental hypertension ${ }^{4-7)}$.

A large number of studies evidence the capacity of the kidney to produce NO and its relevant role in renal function $^{8-12)}$. It has been demonstrated that the kidney is very sensitive to the reduction of $\mathrm{NO}$, as low doses of NOS inhibitors reduce sodium and water excretion without affecting renal hemodynamics or systemic arterial pressure $^{8)}$. The kidney has an intrinsic mechanism, in which an increased renal perfusion pressure promotes 
sodium excretion, a phenomenon called pressure natriures is ${ }^{13)}$. $\mathbf{t}$ has been shown that chronic inhibition of NO synthesis impairs sodium excretion, resulting in right shift of the pressure-natriuresis curve and hypertens $\operatorname{ion}^{14)}$. In spontaneously hypertensive rats (SHR), pressurenatriures is is also blunted ${ }^{15)}$ and papillary blood flow is reduced $^{16)}$. Recently, Larson et $\mathrm{al}^{17)}$ have shown that administration of $\mathrm{L}$-arginine to SHR restores the pressure-dependent increase in renal medullary hemodynamics in association with restoration of pressure-natriuresis. These results suggest that a defective NO pathway may be involved in the blunted pressure-natriuresis. However, the precise status and role of the NO-cGMP pathway in the kidney in SHR is not clear.

The present study was aimed at investigating whether the hypertension is related with an altered activity of NO system in the kidney of SHR. The expression of NOS isozymes and tissue NO levels were determined in the kidney isolated from SHR and their normotens ive control Wistar- Kyoto rats (WKY) by Western blot analys is.

\section{MATERIALS AND METHODS}

\section{Animals}

Experiments were carried out using adult (12-week old) male SHR and WKY. Systolic blood pressure was measured in a conscious state by the tail-cuff method. Rats were killed by decapitation. Blood was collected from the trunk, and centrifuged $(3,000 \mathrm{rpm}$ for $30 \mathrm{~min}$ ) for the determination of plasma NO contents. Kidneys were rapidly removed, immediately frozen in liquid nitrogen and stored at $-80^{\circ} \mathrm{C}$ until extraction.

\section{Colorimetric Assay of Nitrite/Nitrate}

NOx (nitrite/nitrate) contents in the kidney and plasma were measured with a colorimetric nitric oxide assay kit (Oxford). A microplate was used to perform enzyme reactions in vitro. For spectrophotometric assay of nitrite with Griess reagent, $80 \mathrm{ml}$ MOPS (50 mmolL)EDTA (1 mmolL) buffer and $5 \mu \mathrm{l}$ tissue samples were added to wells. Nitrate reductase $(0.01 \mathrm{U})$ and $10 \mu \mathrm{NADH}(2$ mmolL) were added to the reaction mixture, and the plate was shaken for 20 minutes at room temperature. Color reagents, sulfanilamide and $\mathrm{N}$-(1-Naphthayl) ehylenediamine dihydrochloride were added, and absorbance values at $540 \mathrm{~nm}$ were read in a microtiter plate reader (Bio- Rad model 3550). The concentration of nitrite/nitrate was estimated from a standard curve, which was constructed with the use of standard reagents included in the assay kit.

\section{Prote in preparation}

The cortex, outer medulla and inner medulla from frozen kidney tissues were dissected and were homogenized with Polytron homogenizer at 3,000 rpm in a solution containing $250 \mathrm{mmo} / \mathrm{L}$ sucrose, $1 \mathrm{mmo} / \mathrm{L}$ EDTA, $0.1 \mathrm{mmo} / \mathrm{L}$ phenylmethylsulfonyl fluoride and 50 mmolL potassium phosphate buffer at $\mathrm{pH}$ 7.6. Large tissue debris and nuclear fragments were removed by two consecutive low speed centrifuge spins $(3,000 \mathrm{~g}, 5$ $\mathrm{min} ; 10,000 \mathrm{~g}, 10 \mathrm{~min})$. The protein concentration of the homogenate was determined by the method of Bradford $^{18)}$, with bovine serum albumin as a standard. In the case of cortex, the membrane-bound protein was further centrifuged at $100,000 \mathrm{~g}$ for $60 \mathrm{~min}$. The pellet was resuspended for protein blotting of ecNOS and the supernatant was used for blotting of bNOS and iNOS.

\section{Western blot analys is}

Protein samples were electrophoretically sizeseparated with a discontinuous system consisting of a $7.5 \%$ polyacrylamide resolving gel and $5 \%$ polyacrylamide stacking gel. High-range molecular weight markers (Biorad; Hercules, CA, USA) were loaded as size standard. An equivalent amount of total tissue protein $(100 \mu \mathrm{g})$ was loaded on each lane. After separation, the proteins were electrophoretically transferred to a nitrocellulose membrane at $20 \mathrm{~V}$ overnight. The membranes were washed in Tris-based saline buffer ( $\mathrm{pH}$ 7.4) containing $1 \%$ Tween-20 (TBST), blocked with 5\% nonfat milk in TBST for one hour and incubated with a $1: 2,000$ dilution of monoclonal mouse anti-bNOS, anti-ecNOS and anti NOS antibodies (Transduction Laboratories; Lexington, KY, USA) in $2 \%$ nonfat milkTBST for one hour at room temperature. The membranes were then incubated with a horseradish peroxidase-labeled goat anti- mouse $\mathrm{gG}(1: 1,000)$ or goat anti-rabbit $\mathrm{ggG}$ in $2 \%$ nonfat milk in TBST for 2 hours. The bound antibody was detected by enhanced chemiluminescence on X-ray film or hyperfilm (Amersham, Little Chalfont, Buckinghamshire, England). 


\section{ALTERED RENAL EXPRESSION OF NITRIC OXIDE S YNTHASE}

IS OZ YMES IN SPONTANEOUSLY HYPER TENSIVE RA TS

The membranes were stripped between incubations with different antibodies in a Tris-buffered solution containing $2 \%$ sodium dodecyl sulfate and 100 mmolL $\beta$ - mercaptoethanol at $50^{\circ} \mathrm{C}$.

\section{Statistical analys is}

The results are presented as means \pm SEM. The significance of the differences was analyzed by the Student's $t$-test of unpaired data.

\section{RES ULTS}

\section{Blood pressure and plasma $\mathrm{NO}$ concentration}

Body weight, systolic blood pressure and heart rate in SHR and WKY were summarized in Table 1. Systolic blood pressure and heart rate were higher in SHR compared with those in WKY. The plasma NOx (nitrite/nitrate) concentration was significantly higher in SHR compared with that in WKY (Fig. 1).

Table 1. Body weight (BW), systolic blood pressure (S BP) and heart rate (HR), in spontaneously hypertensive rats (SHR) and Wis ta r- Kyoto (WKY)

\begin{tabular}{cccc}
\hline & BW (g) & SBP (mmHg) & HR (beats/min) \\
\hline WKY & $315 \pm 15$ & $13 \pm 5$ & $360 \pm 23$ \\
SHR & $288 \pm 8$ & $223 \pm 7^{* *}$ & $440 \pm 4^{*}$ \\
\hline
\end{tabular}

Values are means \pm SEM. $\mathrm{n}=6$ in each group. ${ }^{*} \mathrm{p}<0.05$, *te $<<0.01$; compared with WKY.

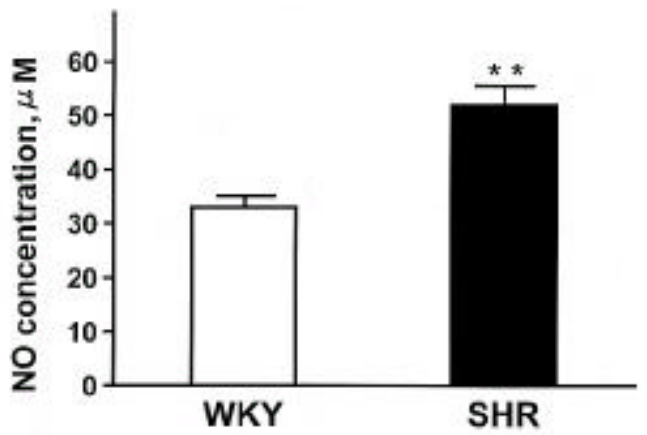

Fig. 1. Plasma NOx concentrations (nitrite/nitrate) in SHR and WKY rats. Each column represents mean \pm SEM from 6 experiments. $* \mathrm{p}<0.01$, compared with control.
2. NOx contents and NOS expression in the kidney

Fig. 2 shows NOx contents in the inner medulla, outer medulla and cortex of the kidney in SHR and WKY. The $\mathrm{NO} x$ contents were higher in the outer medulla and cortex of the kidney by about $50 \%$ and $60 \%$, respectively, in SHR compared with those in WKY.

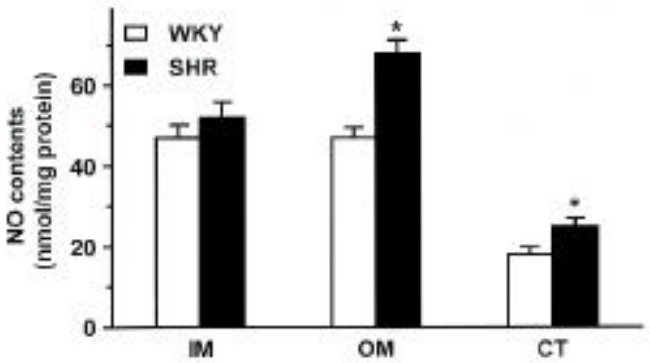

Fig. 2. NOx contents in the inner medulla (IM), outer medulla $(\mathrm{OM})$ and cortex $(\mathrm{CT})$ of the kidney in SHR and WKY rats. Each column represents mean \pm SEM from 6 experiments. ${ }^{*} \mathrm{p}<0.05$, compared with control.

Three isoforms of NOS (bNOS, iNOS,ecNOS) were determined in the renal cortex and outer and inner medulla of SHR and WKY by Western blot analysis (Fig. 3). Anti-bNOS, anti-iNOS and anti-ecNOS antibodies recognized prote in bands with molecular sizes of 155, 130 and $140 \mathrm{kDa}$, respectively. Fig. 4 shows denstometric analys is of NOS in the kidney. ecNOS prote in expression did not significantly differ between SHR and WKY. However, bNOS proteins were expressed higher in the outer medulla and cortex by $80 \%$ and $70 \%$, respectively, and iNOS proteins were higher in the inner medulla, outer medulla and cortex by $95 \%, 135 \%$ and $50 \%$, respectively, in SHR.

\section{DIS CUS S ION}

I is well known that acetylcholine-induced vasodilation is impaired in $\mathrm{SHR}^{19-21)}$, however, of which precise mechanisms are not fully understood. A growing number of studies ${ }^{22-25)}$ have demonstrated that NO synthesis may be increased in SHR. It was reported that an inhibition of NOS produced a greater reduction of vasorelaxation to acetylcholine $^{26)}$ and an exaggerated hypertension in $\mathrm{SHR}^{27)}$. Furthermore, the present study showed that plasma NOx (nitrite/nitrate) concentration and NOx 


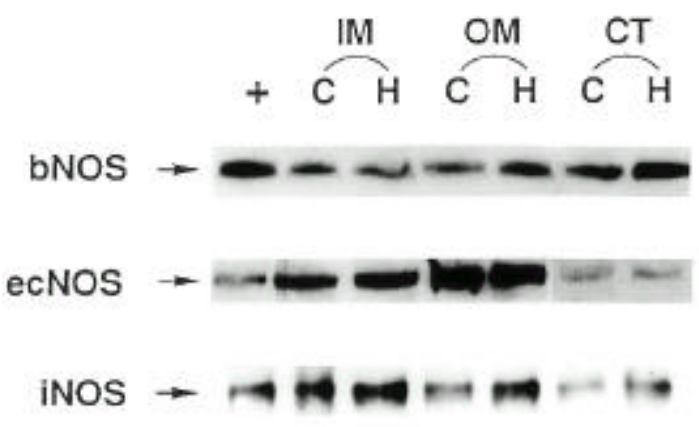

Fig. 3. A representative Western blot of total tissue prote in $(100 \mu \mathrm{g})$ extracted from inner medulla (IM), outer medulla (OM) and cortex (CT) of the kidney of SHR (H) and WKY rats (C). Rat pituitary (bNOS), induced macrophage (iNOS) and human endothelial cell (ecNOS) were added as positive control (+) for each NOS isoform

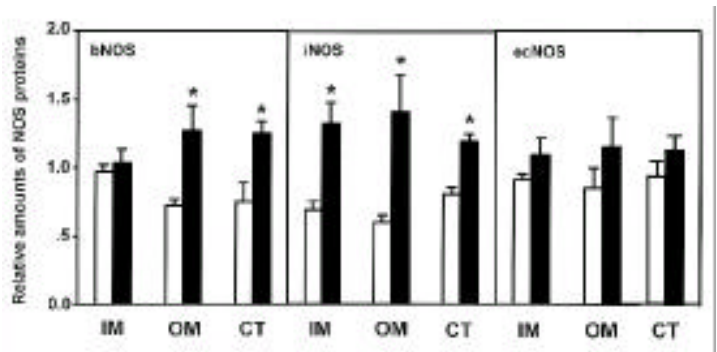

Fig. 4. Densitometric analys is of bNOS, iNOS, and ecNOS in inner medulla (IM), outer medulla (OM) and cortex (CT) of the kidney. Open column indicates WKY rats and hatched column indicates SHR. Each point represents mean \pm SEM from 6 experiments. " $\mathrm{p}<0.01$, compared with control.

contents in the kidney were significantly higher in SHR compared with those in WKY. It has been known that the release of NO by endothelial cells can be altered by changes in blood flow ${ }^{28)}$, and their mRNA and prote in for ecNOS can be induced by mechanical forces ${ }^{29)}$. The augmented expression of ecNOS may play an important role in the compensatory mechanisms to counteract the hypertension.

The present study showed that renal NOx contents and NOS protein expression in the medulla were higher than in the cortex. These findings are consistent with previous studies revealing the largest signal for constitutive NOS prote in expression in the inner medullary collecting duct ${ }^{30)}$, and with the report showing the highest a mount of cGMP in the inner medulla, when stimulated with acetylcholine ${ }^{31}$. These results suggest that the medullary NO system plays a more important role in renal function, such as control of sodium and water excretion.

Tubuloglomerular feedback (TGF) is the critical component of a negative feedback control system that effectively buffers the hemodynamic influences on GFR and stabilizes the amount of $\mathrm{NaCl}$ entering the distal nephron $^{32)}$. In the kidney, bNOS protein has been demonstrated exclusively in the macula densa cells, and NO produced in these cells counteract the TGF-mediated vas oconstriction $^{33,34)}$. This finding indicates that, under normal conditions, NO is one of major determinants of TGF sensitivity. SHR are known to have a sensitive TGF response during development of hypertension ${ }^{35,36)}$. The exaggerated response could contribute to a lower glomerular filtration and, perhaps, to the development of hypertension ${ }^{37)}$. Thorup and Person ${ }^{38)}$ compared the effects of intratubular inhibition of NO by $\left[\mathrm{N}^{\omega}\right.$ - nitro- Larginine (L-NNA)] on the TGF between SHR and WKY rats, and showed that L-NNA did not change either sensitivity or the magnitude of the TGF response in SHR, whereas their normotensive control strains responded with a very strong resetting toward higher sensitivity. This finding indicates that NO-mediated vasodilation that counteracts TGF-induced vasoconstriction of the afferent arteriole is less pronounced in SHR than in their normotensive controls. Our study demonstrated that the expression of bNOS prote in in renal cortex and outer medulla in SHR was higher than in WKY. Since bNOS in macula densa seems to attenuate the afferent arteriolar constriction induced by the $\mathrm{TGF}^{33,34)}$, enhanced bNOS expression would be expected to increase GFR and sodium excretion which act as a compensatory function opposing the hypertension.

Pressure-natriuresis is associated with significant increase in vasa recta blood flow $^{39)}$. I has been postulated that the mechanism, through which changes in medullary hemodynamics result in pressure-dependent increase in urinary sodium excretion, is due to transmission of pressure from the systemic circulation to the renal interstitium through the renal microcirculation ${ }^{40}$. In SHR, papillary blood flow in response to increased renal perfusion pressure is reduced, and pressurenatriuresis is blunted ${ }^{41)}$. Hence, the attenuated response 


\section{ALTERED RENAL EXPRESSION OF NITRIC OXIDE S YNTHASE}

IS OZ YMES IN SPONTANEOUSLY HYPERTENSIVE RA TS

of renal medullary hemodynamics to change in renal perfusion pressure has been postulated to be causally linked to the abnormal pressure natriuresis in the $\mathrm{SHR}^{41,42)}$. The restoration of the vasa recta hemodynamic response with $\mathrm{L}$-arginine in SHR supports a role for NO in the regulation of medullary blood flow $^{17)}$. Ikenaga et $\mathrm{at}^{43)}$ reported that intravenous administration of $\mathrm{L}$-arginine increase urinary excretion of NO metabolites in normotensive animals, and in SHR to a similiar degree, suggesting that, in the SHR, the ability to synthesize NO is preserved but the renal response to $\mathrm{NO}$ is impaired. Our study also demonstrated that the basal production of NO was higher in the kidney in SHR compared with that in WKY. bNOS proteins were expressed higher in the outer medulla and cortex, and iNOS proteins were higher in the inner medulla, outer medulla and cortex in SHR. These results suggest that impaired effect of NO or activation of other vasoconstricting factors may be responsible for the blunted pressure natriures is in SHR rather than defective $\mathrm{NO}$ production.

In conclusion, the NO generation may not be impaired, but rather increased in the kidney of SHR. $\mathbf{I}$ is likely that an altered expression of NOS isozymes plays a counter-regulatory role secondary to the hypertension in SHR.

\section{ACKNOWLEDGEMENT}

This work was supported by research grants from Korea Science and Engineering Foundation(97-040309-01-3) and Chonnam University Hospital Research Institute of Clinical Medicine(CUHRF Y- 98003).

\section{REFERENCES}

1. Moncada S, Higgs A: The L-arginine-nitric oxide pathway. N Engl J Med 329: 2002-20 D, 1993

2. Moncada S, Palmer RM, Higgs EA: Nitric oxide: physiology, pathophysiology and phamacology. Phamacol Rev 43: 109- 142, 1991

3. Forstermann U, Mulsch A, Bohme E, Busse R: Stimulation of soluble guanylate cyclase by an acetylcholine-induced endothelium-derived factor from rabbit and canine arteries. Circ Res 58: 53 1-538, 1986

4. Winquist RJ, Bunting PB, Baskin EP, Wallace AA: Decreased endothelium-dependent relaxation in New Zealand genetic hypertensive rats. J Hypertens 2: $541-545, \quad 1984$
5. De Mey JG, Gray SD: Endothelium-dependent reactivity in resistance vessels. Prog Appl Microcirc 8: 18 1- 187, 1985

6. Van De Voorde J, Leusen I: Endothelium-dependent and independent relaxation of aortic rings from hypertensive rats. Am J Physiol 250: H7 11-H7 17, 1986

7. Otsuka U, Dipiero A, Hirt E, Brennaman B, Lockette $\mathrm{W}$ : Vascular relaxation and $c G M P$ in hypertension. Am J Physiol 254: H 163-H 169, 1988

8. Salazar FJ, Alberola A, Pinilla JM, Romero JC, Quesada T: Salt-induced increase in arterial pressure during nitric oxide synthesis inhibition. Hypertension 22 : 49-55, 1993

9. Biondi ML, Botterman RJ, Romero JC: Zonal changes of guanidine 3,5'-cyclic monophosphate related to endothelium-derived relaxing factor in dog renal medulla. Renal Physiol Biochem 15: 1-7, 1992

10. Cowley AW, Mattson DL, Lu S, Roman RJ: The renal medulla and hypertension. Hypertension 25: 663-673, 1995

11. Mattson DL, Lu S, Nakanishi K, papanek PE, Cowley AW Jr: Effect of chronic medullary nitric oxide inhibition on blood pressure. Am J Physiol 266: H 19 18-H 1926, 1994

12. Fenoy FJ, Ferrer P, Carbonell L, Salom MG: Role of nitric oxide on papillary blood flow and pressure natriuresis. Hypertension 25: 408-4 14, 1995

13. Kaloyanides GJ, DiBona GF, Raskin P: Pressure natriuresis in the isolated kidney. Am J Physiol 220: 1660-1666, 1971

14. Mattson DL, Lu SH, Nakanish K, Papanek PE, Cowley AW Jr: Effect of chronic renal medullary nitric oxide inhibition on blood pressure. Am J Physiol 266: H 19 18-H 1926, 1994

15. Roman RJ, Cowley AW: Abnomal pressurediuresis-natriuresis response in spontaneously hypertensive rats. Am J Physiol 248: F 199-F205, 1985

16. Roman RJ, Kaldunski ML: Renal cortical and papillary blood flow in spontaneously hypertensive rats. Hypertension 11: 657-663, 1988

17. Larson TS, Lockhart JC: Restoration of vasa recta hemodynamics and pressure natriuresis in SHR by L-arginine. Am J Physiol 268: F907-9 D, 1995

18. Bradford MM: A rapid and sensitive method for the quantitation of microgram quantities of protein utili ing the principle of protein-dye binding. Ann Biochem 1976; $72: 248-254.1976$

19. Ito S, Carretero OA: Impaired response to 
acetylcholine despite intact endothelium-derived relaxing factornitric oxide in isolated microperfused afferent arterioles of the spontaneously hypertensive rats. J Cardiovasc Phamacol 20 (Suppl R): S 187-S 189, 1992

20. Angus JA, Dyke AC, Jennings GL, Korner PI, Eudhir $\mathrm{K}$, Ward JE, Wright CE: Release of endotheliumderived relaxing factor from resistance arteries in hypertension. Kidney Int Suppl 37: S73-78, 1992

21. Tschudi MR, Mesaros S, Uischer TF, Malinski T: Direct in situ measurement of nitric oxide in mesenteric resistance arteries. Increased decomposition by superoxide in hypertension. Hypertension 27: 32-35, 1996

22. Wu CC, Hong HJ, Chou TC, Ding YA, Yen MH: Evidence for inducible nitric oxide synthase in spontaneoush hypertensive rats. Biochem Biophys Res Commun 228: 459-466, 1996

23. Yen MH, Liu YC, Hong HJ, Sheu JR, Wu CC: Role of nitric oxide in lipopolysaccharide-induced mortality from spontaneousb hypertensive rats. Life Sci 60: 223- 239, 1997

24. Junquero DC, Shini VB, Scott Burden T, Vanhoutte PM: Enhanced production of nitric oxide in aortae from spontaneousb hypertensive rats by interleukin-1 beta. Am J Hypertens 6: 602-610, 1993

25. Nava E, Linas MT, Gonzalez JD, Salazar FJ : Nitric oxide synthase activity in renal cortex and medulla of nomotensive and spontaneousb hypertensive rats. Am J Hypertension 9: R36- 239, 1996

26. Lee L, Webb RC: Endothelium-dependent relaxation and L-arginine metabolism in genetic hypertension. Hypertension 19: 435-44 1, 1992

27. Lacolley PJ, Lewis SJ, Brody MJ : $L$ - $N^{G}$-nitro arginine produces an exaggerated hypertension in anesthetized SHR. Eur J Phamacol 197: 239-240, 1991

28. Buga GM, Gold ME, Fukuto JM, Ignarro L: Shear stress-induced release of nitric oxide from endothelial cells grown on beads. Hypertension 17: 187- 193, 1991

29. Sessa WC, Pritchard K, Seyedi N, Wang J, Hintze $\mathrm{TH}$ : Chronic exercise in dogs increases coronary vascular nitric oxide production and endothelial cell nitric oxide synthase gene expression. Circ Res 74: 349-353, 1994

30. Terada Y, Tomita K, Nonoguchi H, Marumo F: Polymerase chain reaction localization of constitutive nitric oxide synthase and soluble guanylate cyclase messenger RNAs in microdissected rat nephron segments. J Clin Invest 90: 659-665, 1992

31. Biondi ML, Bolterman RJ, Romero JC: Zonal changes of guanidine 3,5'-cyclic monophosphate related to endothelium-derived relaxing factor in dog renal medulla. Renal Physiol Biochem 15: 16-22, 1992

32. Wilcox CS, Welch WJ: TGF and nitric oxide: effects of salt intake and salt-sensitive hypertension. Kidney Int Suppl 55: S9-S 13, 1996

33. Braam B, Koomans HA: Nitric oxide antagonizes the actions of angiotensin II to enhance tubuloglomerular feedback responsiveness. Kidney Int 48: H06-1411, 1995

34. Wilcox CS, Welch WJ, Murad F, Gross SS, Taylor G, Levi R, Schmidt HH: Nitric oxide synthase in macula densa regulates glomerular capillary pressure. Proc Natl Acad Sci USA 89: 11993-11997, 1992

35. Dilley JR, Arendshorst WJ : Enhanced tubuloglomerular feedback activity in rats developing spontaneous hypertension. Am J Physiol 247: F672-F679, 1984

36. Dilley JR, Stier CT, Arendshorst WJ: Abnomalities in glomerular function in rats developing spontaneous hypertension. Am J Physiol 246: F 2-20, 1984

37. Ushiogi Y, Haberle DA: Hyperreactivity of tubuloglomerular feedback in chronically salt-loaded spontaneous hypertensive rats. Kidney Int Suppl 32: S H2-S H7, 1991

38. Thorup C, Persson AE: Impaired effect of nitric oxide synthesis inhibition on tubuloglomerular feedback in hypertensive rats. Am J Physiol 271: F246-F252, 1996

39. Farrugia E, Lockhart JC, Larson TS: Relation between vasa recta blood flow and renal interstitial hydrostatic pressure during pressure natriuresis. Circ Res 71 : $1153-1158,1992$

40. Knox FG, Mertz JI, Burnett JC, Haramati A: Role of hydrostatic and oncotic pressures in renal sodium reabsoption. Circ Res 52: 491-500, 1983

41. Roman RJ, Cowley AW, Garcia- Estan J, Lombard $\mathrm{JH}$ : Pressure diuresis in volume expanded rats. Cortical and medullary hemodynamics. Hypertension D: $168-176,1988$

42. Gebremedhin D, Fenoy FJ, Harder DR, Roman RJ: Enhanced vascular tone in the renal vascularture of spontaneously hypertensive rats. Hypertension 16: 648-654, 1990

43. Ikenaga H, Suzuki H, Is hii N, Saruta I: Role of NO on pressure-natriuresis in Wista-Kyoto and spontaneously hypertensive rats. Kidney Int 43: 205-2 11, 1993 